\title{
Argumentos em torno da possibilidade de infecção por DST e Aids entre mulheres que se autodefinem como lésbicas
}

\author{
| ${ }^{1} \mathrm{G}$. Almeida |
}

Resumo: A produção acadêmica motivada pela epidemia de HIV e Aids impulsionou as pesquisas relativas à sexualidade, configurando novos campos de investigação, em especial sobre os "gays". No entanto, não é significativa no Brasil a produção acadêmica que aborde a vulnerabilidade às DSTs a partir da identidade "lésbica". A saúde sexual das mulheres presumidamente heterossexuais tendeu a permanecer subsumida à exclusiva preocupação com a reprodução ao longo da trajetória das políticas de atenção à saúde das mulheres, mesmo frente à Aids. D e forma ainda mais acentuada que a sexualidade feminina heterossexual, a homossexualidade feminina tendeu à invisibilidade na sociedade brasileira e frente ao discurso médico-ginecológico. 0 advento da epidemia contribuiu para a manutenção desta invisibilidade, por força da crença de que o "corpo lésbico" seria o único corpo infenso à infecção pela via sexual. A hipótese que norteou o presente trabalho está calcada na ideia de que a vulnerabilidade das lésbicas é o "passaporte" para a afirmação/inclusão de um dado marco identitário na agenda de políticas públicas.

> Palavras-chave: Homossexualidade feminina; doenças sexualmente transmissíveis; Aids; Brasil. 


\section{Apresentação}

A produção acadêmica motivada pela epidemia de H IV eAids impulsionou, nas últimas décadas, as pesquisas relativas à sexual idade, configurando novos campos, em especial o dos estudos "gays". No entanto, não é ainda expressiva no Brasil a produção acadêmica sobre a vulnerabilidade das mulheres que se definem como lésbicas às DST e a Aids. M esmo a saúde sexual das mulheres que se definem como heterossexuais permaneceu subsumida à preocupação com a reprodução ao longo da trajetória das políticas de atenção à saúde das mulheres.

D e forma ainda mais acentuada que a sexualidade feminina heterossexual, 0 comportamento homossexual feminino tendeu historicamenteà invisibilidade no discurso médico-ginecológico. 0 advento da Aids contribuiu para a manutenção desta invisibilidade por força da crença de que o "corpo lésbico" seria o único corpo infenso à infecção pela via sexual.

Em uma tese (ALM EIDA, 2005), busquei compreender o processo de transformação do "corpo lésbico" dos primeiros tempos da epidemia até os dias atuais. $\mathrm{N}$ a apreensão de um contra-discurso vocalizado por O N G slésbicas eal guns técnicos, pude perceber a crescentetransformação do "corpo lésbico" deum corpo "imune" em "vulnerável" à epidemia. A hipótese que norteou aquele trabalho foi que a vulnerabilidade lésbica tem-se tornado um passaporte para a afirmação/ inclusão deste marco identitário na agenda de políticas públicas. N esse sentido, o campo em que se desenha a disputa do "corpo lésbico" faceàs D ST / Aids émarcado pela tensão entre prática sexual eidentidade sexual. A afirmação da vulnerabilidade como "passaporte político" não implica, todavia, sua negação como argumento "técnico", como mostrarei adiante.

Partilho deuma tradição intelectual para a qual a sexualidadeéuma construção social e a própria emergência de um campo de estudos sobre ela pode ser compreendida no contexto da sociedade ocidental do final do século XIX. É na sexualidadequese encontram os dispositivos disciplinaresquetornam as experiências do gênero e da sexualidade centrais para a constituição das identidades. A sexualidade trafega por relações de poder entrecortadas pela classe social, pelo gênero e pela raça/cor dos membros de cada sociedade e é, também, um dos sistemas de hierarquia e dominação que criam, mantêm e reforçam diferenças sociais ${ }^{1}$ (WEEKS, 1999, p. 8; VAN CE, 1995). 
O "corpo lésbico" (no singular) foi uma ficção presente na tese e autorizada pela necessidade de perceber como um determinado grupo (estratégico no estabelecimento público de uma identidade lésbica) se pensa. Se meu objetivo fosse fazer uma etnografia do homoerotismo feminino, em uma de suas múltiplas manifestações, deveria ter começado por delimitar a "subcultura lésbica" à qual estava me referindo e reconhecer a pluralidade de manifestações que 0 homoerotismo ${ }^{2}$ feminino comporta. Porém, o que procurei foi demonstrar como, num dado cenário político ecultural, um grupo de indivíduos que protagonizavam um movimento social em expansão representava seus corpos e suas necessidades de saúde. N 0 âmbito das relações de poder, identidades sociais são elaboradas e se constituem como artefatos nos processos de disputa e negociação. D esta forma, 0 poder esteve presentena pesquisa, não apenas quando foi evocado para justificar a possibilidade de infecção das lésbicas por D ST e Aids, mas também quando foi evocado para negar esta mesma possibilidade. Por esta razão, não houve a preocupação em fornecer a resposta acerca da possibilidade biológica da infecção do "corpo lésbico" por D ST eAids.

Trabalhei a partir deuma categoria fornecida por minhas próprias entrevistadas: a "lésbica". Como todo o trabalho demonstrou, esta é uma identidade mais ou menos aceita pelos diferentes grupos, segmentos e mulheres que "fazem sexo" com mulheres. Durante a tese, realizei uma pesquisa qualitativa e exploratória, considerada a mais ad equada para a investigação de um objeto de estudo marcado pela complexidadee pelo desconhecimento. Para a real ização do trabal ho decampo, optei pela utilização de técnicas de pesquisa combinadas: a observação participante (deeventos organizados por organizações lésbicas e pela Liga Brasileira de Lésbicas), a realização deentrevistas semi-estruturadas egravadas (dez ao todo, junto a ativistas emédicos/as ginecologistas) ea análise documental (deartigos dejornaise revistas, páginas eletrônicas e material gráfico de divulgação das organizações lésbicas, de bases bibliográficas nacionais e internacionais). Este artigo parte de alguns elementos oriundos do quarto e último capítulo da tese, que apresentou uma discussão dos principais argumentos que permitiam sugerir a vulnerabilidade das lésbicas em termos biomédicos, tanto em seu aspecto individual quanto programático. 


\section{Argumentos médicos para um corpo vulnerável}

À luz da ginecologia, a experiência lésbica não esteve historicamente no foco da atenção, pois a reprodução foi o tema fundamental dos estudos e da interven ção médica sobre a mulher, entre o final do século XIX e o começo do século XX, quando se consolidou aquele ramo da medicina. $N$ aquele contexto, coube à medicina, além de identificar os problemas, apontar as intervenções a serem feitas pelos poderes públicos no sentido de melhorar a produção de cidadãos (ROHDEN, 2003, p. 206).

Além da ênfase no corpo feminino como reprodutivo, a homossexualidade era interpretada como mais uma das expressões da ninfomania ou das patologias psiquiátricas, que uma "boa intervenção higienista" poderia suprimir ${ }^{3}$. 0 século XIX foi a época do surgimento de um saber médico sobre a homossexualidade, sobrepondo-se ao teológico e ao popular, pois daí em dianteforam os médicosque reivindicaram a autoridade de falar a verdade sobre a sexualidade. 0 crime exigia a punição, mas a doença exige a cura e a correção (FRY; M acRAE, 1985, p. 61).

A dificuldade de estabel ecer uma identidade lésbica distinta até o século $X X$ implicou um reduzido escrutínio científico destas mulheres. Assim, o "corpo lésbico", diferentemente do "corpo gay", permaneceu por mais tempo como uma "caixa-preta" apenas parcialmente explorada como ferramenta discursiva para a teorização sobre as práticas e comportamentos das mul heres homossexuais. O utrora, ao "corpo lésbico" foi reconhecida uma certa vulnerabilidade, embora não expressa nestes termos. Ao percebêlo como expressão em si de uma patologia, o pensamento médico habilitou-sea intervir sobreele, na perspectiva humanitária de retirar os invertidos e as invertidas das prisões, descobrindo-se a etiologia de suas taras e desvios, senão para curá-los, ao menos para evitar que contaminassem novos e inocentes "adeptos". Percebêlos assim, como corposadoecidos, permitia retirá-los da vulnerabilidade às punições jurídicas e policiais pela via da desresponsabilização. Ao preço da perda da autonomia, a medicalização inocentou o "corpo lésbico", bem como os corpos de outras mulheres, como as infanticidas e praticantes do aborto.

A visão da homossexualidade como doença predominou não apenas no discurso médico, como também tornou-se hegemônica nas sociedades desenvolvidas do mundo ocidental até meados dos anos de 1960. Com a contracultura e os movimentos sociais que contribuíram para a politização de questões que eram 
anteriormente entendidas como pertencentes ao âmbito privado, a sexualidadeea homossexual idade foram projetados à condição de bandeiras dos recém-iniciados movimentos sociais como o feminista, gay e de lésbicas.

A té a década de 1990, no Brasil - a possibilidade de infecção do "corpo lésbico" foi pouco cogitada na cena pública da Aids (na política de saúde e no repertório do próprio movimento homossexual). Esta invisibilidade também teve estreita relação com a forma como foi pensada a propagação do vírus pela epidemiologia: pautada na ideia da necessidade de partilha de fluidos corporais -, a ausência de penetração e de contato com fluidos corporaisfariam do "corpo lésbico" um corpo infenso à infecção por H IV, em sentido inversamente proporcional ao "corpo gay", que foi alçado ao epicentro da epidemia. No processo histórico da epidemia foi ocorrendo, entretanto, a substituição do conceito epidemiológico de "grupos de risco" pelo de "comportamentos de risco". I sto ocorreu a partir da constatação da feminilização, interiorização, juvenilização e expansão da Aids junto ao público que se autodefinia como heterossexual - daí ter-se apresentado também a possibilidade de percepção do "corpo lésbico" como sujeito à infecção e, politicamente, das lésbicas como mais um sujeito da epidemia.

A noção derisco individual foi naquele contexto, deslocada para a nova percepção de vulnerabilidade social, tendo a década de 1990 se constituído portanto, como um momento em que surgiu a tentativa de superar a contradição entre "grupos de risco" e o "público em geral". Tal percepção foi crucial não apenas para a compreensão da dinâmica da epidemia, mas para o desenvolvimento das estratégias bem-sucedidas em diminuir seu avanço (PARKER, 2000, p. 103). No âmbito desta mudança paradigmática, a palavra "vulnerabilidade" foi alçada ao dia-a-dia da sociedade, sobretudo no âmbito dos movimentos sociais. Estes passaram a construir argumentos em torno da vulnerabilidade dos diferentes grupos e identidades por eles representados, tanto no âmbito direto do enfrentamento à epidemia, quanto no eixo mais amplo da proposição de políticas públicas para contemplar diferenças e reparar desigual dades.

$\mathrm{O}$ conceito de vulnerabilidade teve origem na área dos $\mathrm{D}$ ireitos $\mathrm{H}$ umanos e foi incorporada por M ann e colaboradores (1993), que passaram a utilizá-lo na busca de uma avaliação da suscetibilidade de indivíduos ou grupos a um determinado agravo à saúde, considerando três planos independentes de determinação: a individual, a programática e a social. 
D iferentes expressões da vulnerabilidade de saúde das lésbicas ${ }^{4}$ passaram então a ser expressas pelo movimento organizado e pelo discurso de alguns pouco técnicos da área de saúde. $\mathrm{N}$ esta construção persistiu a tensão entre admitir a existência de um grupo social com um mínimo de homogeneidade constitutiva e, simultaneamente, percebê-lo como um dos sintomas de um sistema de dominação capaz de impor a um grupo de indivíduos homogeneidade comportamental e identitária.

A meu ver, essa tensão foi se constituído como um dos entraves a avanços na aval iação da dimensão social do adoecimento das lésbicas. Seas "mulheresquefazem sexo com mulheres" nem sempre se definem e querem ser vistas como lésbicas, torna-se difícil utilizar indicadores capazes de revelar o perfil da população lésbica no que se refere ao acesso à informação, bem como revelar seus gastos sociais e de saúde, seu acesso aos serviços de saúde, seu índice de desenvolvimento humano ea relação entre seus gastos com educação e saúde ${ }^{5}$. Algumas pesquisas têm buscado contornar esta dificuldade com a abordagem de populações prédefinidas, como as participantes das paradas do orgulho eas lésbicas apenadas ou profissionais do sexo. ${ }^{6}$

A visibilidade política da homossexualidade feminina nas últimas décadas (mediante o trabal ho do feminismo edos movimentos gay elésbico) foi propulsora denovos discursos. Entreeles de um discurso médico "alternativo", em oposição a um discurso ginecológico majoritário, para o qual o "corpo lésbico" não évisível. 0 que denominei de "alternativo" é formado por um conjunto de assertivas que conferem inteligibilidade à infecção das mulheres que se definem como lésbicas por DST e Aids, à luz e de forma minimamente coerente com o "discurso competente" da ginecologia e da epidemiologia. À revelia do ainda escasso investimento acadêmico sobre o assunto, foi mapeada uma vasta quantidade de materiais educativos produzidos por uma rede de O N Gs lésbicas, inspirados na experiência das ativistas, no discurso de médicos, na importação de materiais e na replicação de estudos internacionalmente produzidos.

0 discurso alternativo ganha significado quando percebido no interior do cenário político brasilei ro das últimas décadas e em estreita relação com as 0 N G s lésbicas, que buscaram no cenário internacional os primeiros elementos para fazer advocacy da vulnerabilidade de seu público-alvo no que se refere à saúde sexual. N um momento posterior, o movimento também buscou interlocução com o M inistério da Saúde e, para ampliar a possibilidade de elaborar materiais 
e difundir informações com legitimidade científica, a colaboração pontual de alguns ginecologistas. Alguns destes passaram a ser profissionais de referência para as 0 N G s lésbicas na produção de seus materiais e no encaminhamento de lésbicas a seus consultórios.

O surgimento das O N G sAids ${ }^{7}$ no final da década de 1980 eo estabelecimento de sua relação com o Estado brasileiro na década de 1990, principalmente através de projetos destinados à prevenção da Aids e da constituição de redes de proteção social para os(as) infectados(as), entre outras iniciativas bem-sucedidas, tiveram forte influência nos movimentos sociais ${ }^{8}$ organizados sobre a identidade sexual de seus integrantes (ZAQ UIEU; TERTO JR., 2002, p. 37).

A influência da epidemia sobreos movimentosorganizadosa partir da identidade sexual incidiu especialmentesobre o movimento gay que- como outrosmovimentos sociais na década de 1990 - passou a se constituir edesenvolver suas ações quase que exclusivamenteatravés das $0 \mathrm{~N} \mathrm{G} \mathrm{s.} \mathrm{Estas,} \mathrm{de} \mathrm{maneira} \mathrm{geral} \mathrm{começaram} \mathrm{a} \mathrm{seexpandir}$ ainda na década de 1980 na cena pública brasileira, mas a partir de 1990 passaram a ser "quase substitutas dos movimentos sociais" (GOH N , 2000, p. 28).

Embora nos primeiros tempos da epidemia, o movimento gay tenha optado por dissociar o estigma da Aids do "corpo gay", esta posição se alterou ao longo da década de 1990, quando os gays voltaram à tônica dos discursos das 0 N G sAids, como vimos por exemplo, na C arta deC uritiba, redigida duranteo VIII Encontro Brasileiro de G ays e Lésbicas (1995). Foi também naquele período que as O N G s lésbicas gradativamente começaram a vocalizar um discurso próprio na discussão pública do "corpo lésbico" em sua relação com a Aids e as demais D STs, o que se tornou uma das princi pais estratégias de afirmação do "direito à saúde sexual".

Em 1994, uma publicação do Coletivo de Feministas Lésbicas (CFL) afirmou que com relação à Aids eao H IV existia "uma lacuna, completa ausência de serviços de educação e prevenção adequada às lésbicas, no combatenão só daAids, mas das DSTs". A publicação afirmou a importância da temática argumentando que 0 vírus ea Aids estavam se espraiando de forma incontrolável na população brasileira, "sem distinção deorientação sexual, idade, cor, classe social" equeentre as mulheres a incidência vinha aumentando mais rapidamente que entre os homens, sendo portanto, "errôneo acreditar quelésbicas são grupo de risco zero. Somos mulheres que fazemos sexo com outras mulheres que são bissexuais, usuárias de drogas endovenosas, mulheres que recebem transfusões de sangue" (CFL, 1994, p. 20). 
0 início do trabalho de prevenção da infecção por D ST /Aids entre lésbicas confundiu-se com o surgimento de um movimento delésbicas autônomo na cena brasileira contemporânea. C onformenossa hipótese, na origem desta preocupação esteve a influência de gruposinternacionais, especial mentenorte-americanos, com quem alguns poucos grupos mantinham interlocução em torno de 1995, especialmente 0 Grupo Lésbico da Bahia (GLB) e a Rede de Informação Um O utro $O$ Ihar (U O O ). N o caso do G LB, a interlocução com gruposinternacionais foi favorecida pelo fato do grupo ser um desdobramento do $\mathrm{G}$ rupo $\mathrm{G}$ ay da Bahia (G GB), que já fazia parte de uma sólida rede internacional.

A influência do discurso adventício não ocorreu pela vinda de ativistas que difundissem de maneira formal a preocupação com a vulnerabilidade das lésbicas: as informações e o material para sexo seguro vieram "sozinhos", pois pelo GLB passavam com frequência lésbicas estrangei ras, com finalidade de pesquisa e/ou apenas de partici pação nas atividades. A ida de militantes brasil ei ras para o exterior também foi um veículo para assimilação das novas ideias, embora não se saiba ao certo se estas eram militantes feministas, lésbicas ou ambas.

0 conhecimento técnico, bem como os primeiros materiais destinados à prevenção foram obtidos, portanto, através de militantes vindas do exterior. D estacou-se a U 00 na construção desta nova temática de atuação das O N G sena definição de um modelo de intervenção sobre a questão que foi replicado por outrasorganizações. Como parte destemodelo de intervenção/prevenção, surgiram as primeiras oficinas nos grupos brasileiros voltadas à prevenção da infecção das lésbicas por D ST, H IV e Aids, ainda utilizando-se de materiais estrangeiros.

D epois desse período inicial, começou a difusão de materiais gráficos dos próprios grupos sobre o tema (panfletos e cartilhas) e o trabalho de adaptação de materiais para sexo seguro ou mais seguro. As experiências da U 00 e a do G LB provocaram uma "febre generalizada" de tratar a saúde sexual nas O N G s lésbicas. Os materiais gráficos do GLB tiveram a especificidade de trabalhar concomitantemente imagens de casais de lésbicas sugestivas de diferenças raciais presentes nestes relacionamentos afetivos e/ou sexuais. Segundo uma das responsáveis pelo GLB à época, o grupo se esforçava por vencer a "barreira" na discussão de várias questões envolvendo sexualidade das lésbicas, buscando também elaborar modelos de oficinas de sexualidade que fossem mais eficazes na relação com seu público. A maioria delas começava com a abertura de um dirigente seguida 
deuma apresentação individual das presentes e da pactuação de que haveria sigilo sobre o que fosse ali discutido.

Também a publicação do CFL registrou que em, São Paulo, mulheres preocupadas com a necessidade de informar e prevenir o HIV/Aids vinham realizando oficinas de sexo seguro para mulheres que se definiam como lésbicas ou bissexuais. O CFL afirmou ainda que somente com "leituras das publicações feitas pelas próprias lésbicas em suas revistas ou boletins, que encontramos artigos esclarecendo sobre doenças sexualmente transmissíveis, prevenção de câncer ginecológico e de mama e controle da Aids" (1994, p. 21). U ma das estratégias então adotadas pelo grupo para a superação do constrangimento que a discussão despertou foi a produção de um livro contendo dinâmicas próprias para a discussão de sexualidade, onde o uso de revistas pornográficas, por exemplo, era um recurso de provocação do debate e de rompimento com o silêncio.

Aospoucos, enão apenas para o C FL, a ênfaseinicial na Aidsfoi sendo substituída pela consciência de que talvez o problema das demais doenças sexualmente transmissí veis fosse uma questão mais pertinente para a maioria das mulheres que se definem como lésbicas, principal mente porque não havia qual quer constatação, no Brasil, de casos reais de infecção por H IV de uma mulher a outra. Paralelamente ao trabal ho imediato dos grupos com o tema, começou a ocorrer a replicação das experiências em grupos de lésbicas ${ }^{9}$ recém-constituídos. Até 1994, aproximadamente, as lideranças destes grupos eram figuras dispersas em grupos mistos (formados por gays e lésbicas ou por feministas e lésbicas) e não havia momentos de articulação nacional. É correto portanto, afirmar que não havia à época um sólido movimento de lésbicas com características autônomas no Brasil.

Durante um Encontro da ILGA ocorrido no Rio de Janeiro em 1995, a expressividade dos grupos de lésbicas negras cariocas foi percebida pelas participantes e ocorreram duas primeiras tentativas de articulação nacional de lideranças exclusi vamente lésbicas. A primeira tentativa foi a de organizar e criar a infraestrutura necessária ao envio de um grupo de lideranças lésbicas brasileiras à Conferência de M ulheres de Beijing que aconteceria pouco tempo depois. $A$ segunda tentativa foi articular uma Secretaria N acional de M ulheres da ILGA, para a realização de um encontro nacional só de lésbicas. A organização e criação da infraestrutura para a ida a Beijing ficou a cargo de lideranças paulistanas; a segunda tarefa coube às lideranças cariocas. 
A ida a Beijing para participarem de forma organizada da IV Conferência $M$ undial sobre a M ulher não aconteceu ${ }^{10}$ e ocorreram vários conflitos entre as lideranças, conflitos que redundaram no descredenciamento das lideranças cariocas junto à ILGA para a realização do encontro. Ainda assim, a ideia de um encontro nacional de lideranças lésbicas se manteve e o grupo de organizadoras cariocas foi buscar junto à CN -D ST /Aids o subsídio financeiro para sua realização.

Atéhoje, os grupos de lésbicas cariocas continuam tendo características muitas vezes distintas dos grupos paulistanos, em função do próprio perfil das frequentadoras, embora já existam também na cena paulista grupos de lésbicas negras e de periferia. Para as ativistas, a forte presença de lésbicas de camadas populares nos grupos cariocas estaria ligada à menor existência de demandas por parte das lésbicas de camadas médias e altas, que já deteriam especialmente informação, a principal oferta dos grupos do Rio de Janeiro.

A história do primeiro Seminário N acional de Lésbicas (SEN ALE) se confundiu com a busca deapoio da CN -D ST /Aids pelas primeiras lideranças lésbicas, com a finalidade de promover aquela primeira articulação nacional do movimento. A visibilidade das lésbicas frente à problemática das DST e da Aids mesclou-se portanto, claramente, à necessidade de oferecer maior visibilidade política às lésbicas.

0 tripé articulador de temas do primeiro SEN ALE enunciava a importância que a demanda por saúde sexual adquiriria dali para a frente no movimento: a saúde como o mais poderoso passaporte para a organização e a visibilidade das lésbicas na arena de definição de políticas públicas. É dialética a relação entre identidade e demanda neste processo em particular, tendo a identidade lésbica se emancipado da identidade homossexual para gerar demandas e vindo a demanda por saúde, de alguma forma, "fabricando" a lésbica brasileira contemporânea na cena política. ${ }^{11}$

Foi assim que, no mesmo ano em que se realizou em São Paulo o VIII Encontro N acional de ONGs Aids, em que o PN -D ST/Aids começou a implementar nacional mentea distribuição gratuita dos medicamentos antirretroviraise em que o Boletim Epidemiológico do M inistério reportou 29.943 casos de Aids (6.587 deles entre mulheres), que a então gestora Lair G uerra de M acedo Rodrigues e 0 movimento de lésbicas brasileiro começaram a trabalhar juntos. A importância da gestora foi ressaltada, porque conforme descreveu uma ativista carioca, seu papel teria sido maior do que o de autorizar simplesmente o financiamento do SEN ALE. 
Lair Guerra instrumentalizou as ativistas para que fossem capazes de elaborar 0 projeto, prérequisito para o apoio institucional do M inistério ao evento. 0 evento, por sua vez, projetou lideranças locais ao âmbito nacional, fez surgir novos grupos e estimulou a progressiva autonomização do movimento em relação aos gays.

O M inistério da Saúde teve papel estratégico na articulação de uma instância deinterlocução permanentecom o movimento delésbicas, conhecida como G rupo $M$ atricial. Tal grupo congregou as principais lideranças do movimento de lésbicas no período para discussão de ações ligadas à CN -D ST / Aids. O utra gestora, Lilia Rossi, coordenadora do grupo, foi também estratégica para o fortalecimento do movimento no período (a exemplo do que Lair G uerra foi inicialmente). ${ }^{12}$ Embora se reconheça a importância do trabal ho político do $\mathrm{G}$ rupo $\mathrm{M}$ atricial que manteve ao longo da segunda metade da década de 1990 e dos primeiros anos seguintes, uma constante interlocução com o M inistério, chama a atenção o fato de que 0 trabalho tinha como intencionalidade produzir demandas de saúde, mas as respostas do Estado não vieram na extensão pretendida pelo movimento. $\mathrm{H}$ á críticas das ativistas aos rumostomados pelo $\mathrm{G}$ rupo $\mathrm{M}$ atricial, por não sentirem como concretos seus resultados. M esmo para quem detém maior conhecimento sobre os rumos posteriores do $G$ rupo, as informações sobre sua efetividade são vagas e informais.

A aproximação das lésbicas com o M inistério da Saúdefoi alvo de críticas dentro do próprio movimento homossexual, sendo estas algumas vezes acusadas de "pegarem carona" na discussão da Aids. As ativistas, mesmo as que não integraram o G rupo M atricial, refutaram tal acusação de oportunismo. Um de seus principais argumentos contrários à crítica é que elas, se não são consideradas especialmente vulneráveis à epidemia por suas práticas sexuais, são ao menos vulneráveis como quaisquer outros segmentos sociais, daí não ter havido nenhuma irregularidadeao demandarem sua inclusão na cena pública da epidemia.

U m aspecto que extrapola o âmbito da saúde propriamente dita, é que a articulação com a CN -D ST / Aids foi para as lésbicas, estratégica, num momento do movimento em que as lideranças ainda não dominavam ferramentas elementares no mundo da organização coletiva contemporânea, como a elaboração de projetos e a construção de demandas. Em decorrência disso, a criação do G rupo M atricial foi indicada por todas as entrevistadas no trabalho de campo, como um marco importante da interlocução com o M inistério da Saúde, responsável por grandes avanços para as 0 N G s lésbicas, sobretudo no campo do financiamento de ações 
como os encontros políticos, a produção de materiais de divulgação dos grupose de prevenção das DST e Aids ea formação de novas lideranças.

As O N G slésbicas puderam, com a introdução (ainda que tímida) do discurso alternativo na agenda pública, alargar os termos da antiga luta do movimento feminista por "direitos sexuais" que, à época do surgimento das primeiras O N Gs Aids (ao contrário do movimento gay), custou a reconhecer na Aidsum problema que dizia respeito às mulheres. Elas têm feito isto, no entanto, por força dos programas preventivos de DST e Aids e não através do PAISM . N ão parece ter havido, por parte dos gestores e executores do Programa de Atenção Integral à Saúde da Mulher (PAISM), a mesma disposição de interlocução que foi determinante na incorporação das lésbicas pela CN -D ST / Aids.

\section{A vulnerabilidade individual das lésbicas}

U ma grandeempreitada do movimento delésbicas hojee, em certa medida, também do pink market, foi a de transformar uma identidade frequentemente vista como reclusa, clandestina e estigmatizada, numa identidade capaz de falar desi, revelarse nos mais diferentes espaços e denunciar antagonistas. A "nova lésbica" tem conseguido ser (re)vista moral e esteticamente e interpretada em al guns contextos como "positiva". U ma das estratégias para que esta nova visibilidade pudesse aos poucos ser construída, foi a rejeição do rótulo da masculinização e o incentivo a uma crescente efeminação das lésbicas.

Entre os vocalizadores de um discurso al ternativo sobre a vulnerabilidade das lésbicas às D STseAids, as mudanças no plano da visibilidade pública das lésbicas também incidiram. 0 primeiro nível pelo qual a vulnerabilidade lésbica pôde ser pensada foi o individual. Trata-se da percepção de que o "corpo lésbico" é, antes de tudo, um corpo feminino (generificado) e, portanto, semelhante aos demais corpos femininos que, historicamente à luz da ginecologia e da higiene, foram vistos como intrinsecamente patológicos (Rohden, 2003). D esta forma, lésbicas puderam ser pensadas como vulneráveis às DST e a Aids por conta de suas especificidades de gênero - anatômicas e/ou culturais que inexoravelmenteas atariam ao gênero feminino. Assim, a gonorreia na mulher seria mais difícil de detectar do que no homem, porque naquela é "muito interna e no homem fica mais claro". Além disso, os homens teriam maior prática de manipulação da própria genitália, em oposição às mulheres. 
Interessanteéqueessa colagem inexorável ao gênero feminino não pareceu favorecer as que se definem como lésbicas na relação com os cuidadores e instituições de saúde. No âmbito da relação estabelecida com os profissionais de saúde, a vulnerabilidade de gênero das lésbicas desapareceria e daria lugar à percepção das mesmas como "não-mulheres", excluídas do acesso aos exames Papanicolaou e de mamas, que são partedo protocolo deexames comum às mulheres. A mesma exclusão seoperaria no momento do climatério: às lésbicasnesta faseda vida, não seria oferecida rotineiramente a opção pela reposição hormonal ou não, nem exames regularmente solicitados ao público feminino daquela faixa etária, como a densitometria óssea.

D e forma complementar, o segundo plano em que as lésbicas foram tomadas como individualmente vulneráveis, relacionou-se ao fato de mais uma vez manifestarem comportamentos comuns à maioria das mulheres, como a resistência à interven ção médica, expressa no não-comparecimento às consultas ginecológicas. Tal resistência seria agravada pela ausência de práticas que levem à prevenção dos agravos que acometem a população feminina em geral . Esta ausência écondicionada não apenas por questões objetivas oriundas da gestão das políticas de saúde mas, principalmente, pela formação e prática dos profissionais que em geral, não priorizariam ações desta ordem. Vale destacar a afirmação de que o baixo índice de casos públicos de Aids entre lésbicas foi atribuído ao fato destas serem classificadas nas unidades de saúde a partir da categoria "sexo" e não da "orientação sexual" (não sendo por isso perguntado se mantêm relações sexuais com outras). Este fato seria tão importante quanto o de que as vias de transmissão são mais escassas entre elas.

0 terceiro plano em que a vulnerabilidade individual das lésbicas foi afirmada foi o das supostas práticas sexuais de risco. N esta lógica, lésbicas seriam vulneráveis porque entrariam em contato com os fluidos uma da outra, tais como o sangue menstrual e o lubrificante vaginal, potencialmente capazes de transportar agentes infecciosos de um corpo a outro, através de pequenos e ocul tos acessos à circulação sanguínea, como as cutículas ("nas mulheres frequentemente aparadas") e a boca (sempre sujeita a ulcerações, fissuras, cáries etc.). 0 sangue foi particularmente destacado pela preocupação com as hepatites. D ada a imprevisibilidade destes acessos à corrente sanguínea, que também podem ser produzidos durante 0 ato sexual (como as esfoladuras), adviria a necessidade de evitar a partilha de acessórios na penetração vaginal ou anal ea recomendação do uso depreservativos masculinos diferentes em cada vagina ou ânus. 
Entre as práticas de risco supostamente mais comuns entre lésbicas, ganharam centralidade o uso de acessórios sexuais como os vibradores, os dildos, os pênis de borracha ou silicone, além de objetos domésticos improvisados para a penetração vaginal ou anal entre mulheres. A pedagogia no uso de acessórios seria um ponto fundamental da lógica da prevenção, porquenos poucos casos em quesecomprovou infecção por H IV entrelésbicas monogâmicas (através degenotipagem, no contexto internacional), esta teria sido a via de infecção.

Como resposta a esses diferentes aspectos da vulnerabilidadeindividual das lésbicas, foram propostas mudanças comportamentais, queincluíram uma variedade de ações: a frequência ao ginecologista eao exame preventivo, a não-escovação dos dentes e 0 não-uso do fio dental antes das relações sexuais (recomendou-se, em substituição, o uso de balas para melhorar o hálito), a não-retirada das cutículas, a abstinência de relações sexuais durante a menstruação e a atenção para algumas práticas sexuais consideradas mais perigosas. Entre estas últimas figuraram a penetração com dedos ou com a mão ea prática da esfregação de uma vulva contra a outra.

A secreção vaginal conteria vírus H IV em menor concentração do que o esperma (argumento frequentementeevocado para minimizar o risco deuma mulher infectar outrem)? Para o discurso alternativo, sim, embora a carga viral da paciente tenha sido destacada como uma variável importante, pois guardaria mai or relação com 0 estado de saúde da paciente do que com o sexo. Além disso, a qual idade da relação sexual também poderia incidir, acentuando o risco de a secreção vaginal tornar-se mais ou menos infecciosa, especialmente se ela foi mais ou menos traumática (com lacerações e/ ou sangue).

A questão éque, especialmenteno material oriundo das 0 N G slésbicas, encontrei a generalização da percepção de que as identidades definem as práticas sexuais. Ser lésbica ou bissexual pressuporia determinadas práticas sexuais (entre elas, a ausência de sexo com homens). As ativistas afirmaram, no entanto, que o argumento em torno da baixa ocorrência de práticas de risco fragiliza-se diante do silêncio que norteia o comportamento das poucas lésbicas publicamentesoropositivas: existeuma dificuldade de saber se foram infectadas porque eram U D I sou porque mantiveram relações sexuais com homens; ou ainda, através de relações de risco com outras mulheres. Estes seriam temas "delicados" e por isso a serem evitados nos grupos de lésbicas, pois eventualmente ameaçariam a relação entre a identidade publicamente assumida e os comportamentos sexuais do cotidiano. 
U ma polêmica, também presentenaliteratura internacional, foi a possibilidade de infecção das lésbicas por vaginose bacteriana (VB), que, assim como a candidíase, não foi considerada uma D ST, mas seria de grande ocorrência entre as lésbicas em vários estudos médicos. A afirmação predominantefoi a de que, embora a candidíase e a vaginose possam não ser estritamente consideradas doenças sexualmente transmissíveis, as mesmas poderiam - por serem infecções - constituir "canais" possíveis de infecção. Alguns estudos epidemiológicos internacionais foram afirmativos de quea VB poderia aumentar a transmissão do H IV em atétrês vezes, bem como a cândidíase. $N$ estes estudos, a hipótese aventada foi que isto ocorreria porque, mesmo não sendo doenças sexualmentetransmissíveis, aVB ea candidíase, causariam um processo inflamatório local, um acúmulo de linfócitos pelos quaiso vírus HIV tem maior tropismo. ${ }^{13}$

A possibilidade de infecção pelo H PV e o consequente acréscimo do risco de câncer de colo uterino também foi campo de vastas especulações. Por este setratar de um vírus de grande propagação e por ser uma crença amplamente difundida, a da menor frequência das lésbicas ao Papanicolaou (tido como principal estratégia de prevenção do câncer de colo uterino), práticas tidas como de grande incidência entre as lésbicas, como o tribadismo, o sexo oral, a penetração e até mesmo a manipulação genital, deveriam estar sob vigilância e inspirar cuidados. 0 scuidados se justificariam em função de o H PV ter períodos de latência longos (atédez anos).

\section{A vulnerabilidade social das lésbicas}

Para além da descrição e da denúncia do potencial infeccioso de determinadas práticas, na afirmação da vulnerabilidade das que se autodefinem como lésbicas, ocorreu o recurso também a comportamentos mais gerais (não diretamente associáveis à sexualidade) característicos de determinados grupos formados por lésbicas, que aumentariam sua vulnerabilidade, como 0 abuso de álcool e drogas ilícitas, ${ }^{14}$ especialmente das injetávess. H ouve inclusive uma interseção sugerida entre os UDI e a incidência de hepatite $C$, mas também a afirmação de que os estudos brasileiros não deixavam clara essa relação entre lésbicas. Estas seriam usuárias mais frequentes de drogas lícitas, como o tabaco e álcool, e também das ilícitas. Isso aumentaria sua propensão a práticas sexuais de risco, tanto por força dealterações no estado de consciência, quanto em função da tendênciaà prostituição ocasional ou frequente, como meio de obtenção de drogas. 
Pôde ser percebido que as recomendações de "sexo seguro" ou "mais seguro" voltadas para lésbicas, foram produzidas a partir de uma discussão sobre as práticas sexuais mais frequentes entre as ativistas do movimento, tal o detalhamento das recomendações, como demonstra um dos panfletos da $\cup 00,,^{15}$ que desenvolveu uma classificação em três divisões das práticas sexuais realizadas entre lésbicas em: "totalmente seguras", "provavelmente seguras" e "não seguras, arriscadas".

A meu ver, a possibilidade de negociação do sexo seguro implícita nos materiais analisados colidia com uma cultura lésbica modelada pelo ethos romântico e pela rígida demarcação de papéis sexuais (ativas e passivas). Além disso, o kit de materiais elaborado para a prevenção pelo M inistério da Saúde (M S), produto da adaptação de materiais preexistentes, ${ }^{16}$ atuava também como um corpo estranho aos casais de lésbicas. 0 kit era (irregularmente) distribuído pelo M S junto a alguns grupos lésbicos e incluía uma pequena tesoura, luvas e até um cortador de unhas, mas não resolvia o problema da inclusão destes materiais na relação sexual, pois seus próprios componentes evocavam a necessidade de uma assepsia racional incompatível com o ideário romântico.

Em outras palavras, existiu uma questão bem objetiva que se interpôs ao uso de materiais de prevenção: as características desses materiais. 0 kit era de grandes proporçõeseimplicava dificuldade para seu acondicionamento (no caso detransporte) e sua ocultação (caso ele não pudesse ser conhecido por familiares e outras pessoas). O smateriais impunham a racionalidade de cortá-losantes da relação sexual, no caso das películas para sexo oral adaptadas decamisinhas ou luvas (o que podia comunicar à parceira uma intenção pré-definida, racional e nada romântica e/ou a discutível disciplina de interromper as atividades eróticas para cortá-los). A maioria das entrevistadas foi unânime em dizer que a criação de materiais a partir de sugestões nativas (como a ideia de uma "cal cinha de látex" lembrada em uma das entrevistas), aliada à construção de novas estratégias de discussão das sexualidades lésbicas, seria o caminho para a garantia de maior efetividade dos materiais.

Reaparece aí também, mutati mutandis, a problemática da negociação do preservativo presente nas análises sobre os limites da prevenção em mulheres autodefinidas como heterossexuais. Além devisualmentedesinteressanteeassociado à doença e à assepsia hospitalar, o uso do material improvisado esbarrava numa dificuldade que transcende a homossexualidade: como modificar, por força de campanhas, hábitos sexuais de pessoas de mais idade, acostumadas a toda uma 
vida de sexo "despreocupado"? As dificuldades do sexo seguro ou mais seguro para lésbicas ou bissexuais corroboraram a prática regular de exames para detecção de DST, Aids e câncer de colo uterino, como a melhor opção de prevenção entre as poucas lésbicas que pensaram sobre a possibilidade de infecção. Para estas, tratavase da incorporação de um rito "pré-sexual", demarcado pela assertiva "me mostra os seus exames e eu mostro os meus".

0 discurso pró-possibilidade de infecção também promoveu a preocupação com a higiene e monitoramento dos sintomas corporais da presença de D ST . 0 melhor monitoramento de sintomas seria o realizado em parceria, pelo casal. Era então acionada a figura da companheira. Recomendando-se que as leitoras se utilizassem da presença da companheira para discutir alterações na cor, espessura e cheiro "dos líquidos que temos na área genital". O recurso à presença da companheira também foi utilizado como estímulo para que lésbicas e bissexuais pudessem "conhecer melhor seus corpos". Recomendou-se o uso do espelho para visualização das partes íntimas, e ainda, que a mulher dividisse "este prazer" com a companheira. Apesar de a figura da companheira surgir nestes momentos, ela não foi incorporada como coadjuvante na erotização das barreiras, como é usual nos materiais elaborados para o público heterossexual. Em apenas um panfleto, a imaginação e a erotização das barreiras apareceram como recurso para motivar a adesão do casal ao sexo mais seguro.

É possível afirmar queo recurso à figura da companheira teria alcancetambém limitado na prevenção de doenças, pois sua evocação estava associada a uma performance do casal em termos igualitários: igual dade na representação corporal das envolvidas, igualdade nas expectativas em torno da relação sexual eigual dade de papéis sexuais. Tanta igualdade teve como pressuposto uma representação da homossexualidade que, embora possa ser incorporada com frequência (mas não necessariamente) ao ethos das camadas médias, não éuma constantena organização dos casais de lésbicas, muitas vezes fundados em um modelo assimétrico.

$\mathrm{N}$ as entrevistas emergiram al gumas práticas nativas de autocuidado, nem sempre conformeas prescrições da literatura médica. Estas práticas deautocuidado recriadas no cotidiano dos encontros afetivos e/ ou sexuais precisariam ser necessariamente discutidas pelos agentes da prevenção, em termos de sua efetividadee como forma de compreensão da percepção de risco de al guns grupos de lésbicas. U ma das práticas descritas, realizada por uma das integrantes de um grupo, consistia 
em selecionar as mulheres com quem gostaria de ter relações sexuais através do olfato: a moça, autodeclarada lésbica, selecionava as possí veis parceiras durante 0 baile, "pegando" (trocando carícias com) a menina e, disfarçadamente, passando a mão em seus órgãos sexuais. A seguir, ela cheirava, e se o cheiro "fosse bom", ela "ficava" (mantinha relações sexuais) com a menina. A ativista que descreveu tal prática disse ter se sentido identificada com ela, porque os cheiros - também para ela - eram elementosindispensáveis do erotismo. Além disso, a atenção aos cheiros da própria vagina e vulva guardaria a força da ancestralidade: para ela, foi uma prática aprendida com a madrasta, que dizia que se podia perceber alterações da saúde cheirando as próprias calcinhas.

Para além do possível abuso de drogas e das dificuldades de elaboração de práticas sexuais mais seguras, a vulnerabilidade social das lésbicas adviria ainda de dois outros condicionantes incidentes sobre elas: as experiências múltiplas de violência e as questões relativas à reprodução.

Diferentes formas de violência atuariam como condicionantes sociais do aumento da sua vulnerabilidade à infecção por D ST /Aids, como por exemplo, na sua forma mais óbvia, a violência sexual. Além do risco de violência sexual, reportado como significativo por ativistas e médicos, as lésbicas seriam mais comumente vitimadas pela ocorrência de situações diversas de preconceito e de discriminação. Além de enfrentarem a negligência do Estado e das empresas privadas em tais situações, o pano de fundo da violência a que as lésbicas estariam submetidas também seria a atuação de profissionais liberais que atuariam à revelia de princípios éticos e fundados em preconceitos.

0 constante menosprezo social acarretaria mais frequentemente nas lésbicas, um sentimento de desprezo por si mesmas do que nas mulheres em geral, este último sentimento sendo apontado por algumas como reflexo na ausência de práticas de autocuidado. As lésbicas estariam mais sujeitas à violência psicológica e seu efeito mais sensível seria um constante sentimento de débito em relação às expectativas sociais em torno do gênero feminino.

As vivências familiares seriam as principais responsáveis pela pouca autoestima daslésbicas, queteriam em suasfamílias de origem experiências de rejeição, maustratos ou sujeição a exploração econômica, a fim de assegurarem aceitação (estas seriam situações totalmente incorporadas ao anedotário dos grupos de lésbicas). Tais experiências também ocorreriam quando estabelecem relações afetivase sexuais: 
experimentam os desafios comuns de estabelecer, manter e romper parcerias, mas as que se autodefinem como lésbicas encontrariam bem menos suporte social para lidar com as perdas oriundas destas experiências. Enunciadas com reservas pelas entrevistadas, as situações de violência doméstica vividas pelos pares de lésbicas seriam outro condicionante de sua vulnerabilidade.

Também foi destacado o risco de infecção por DST eAids no momento em que as autodefinidas como lésbicas, desejam engravidar. 0 fato de a maioria não ter acesso a técnicas de reprodução assistida (RA) remeteria à busca de soluções casei ras para a inseminação como o uso deseringas (com sêmen doado), o recurso às relações sexuais com amigos (heterossexuais, homossexuais ou bissexuais), ou ainda, a opção por relações sexuais impessoais com a final idade exclusiva do engravidamento. U m dos médicos entrevistados chamou atenção para esta questão, evocando o caso de um casal de lésbicas por ele atendidas que relatou ter utilizado como estratégia (malsucedida) para o engravidamento, a conversão de uma delas em profissional do sexo por um dia, numa rua da cidade de São Paulo. A indiferença pelo desejo de reprodução biológica das lésbicas se manifestaria na insensibilidade dos profissionais de saúde e levaria, em casos extremos, os médicos à conclusão da total inutilidade dos ovários e do útero, contribuindo para a prática pouco criteriosa da histerectomia e da ovariotomia (relatada por al guns entrevistados).

0 desejo de reprodução biológica das lésbicas foi um tema que suscitou questionamentos, maisquequalquer outro aspecto dos direitossexuais reivindicado por elas, seja por ser inconcebível por perspectivas mais conservadoras (queassociam a reprodução única e exclusivamente a heterossexual idade), seja porque desconstrói a visão romântica do "homossexual como transgressor". ${ }^{17}$

\section{A vulnerabilidade programática das lésbicas}

Foi central na vulnerabilidade programática das lésbicas o acesso aos serviços públicos de saúde, em especial aos serviços ginecológicos. Especialmente nos serviços públicos, o acesso seria dificultado primeiramente por questões estruturais que dizem respeito às características excludentes do próprio SUS, notadamente, a dificuldade de agendar e conseguir consultas ginecológicas regulares na rede de atendimento primário. N um contexto em que a escassez (de profissionais e consultas) é básica, considerar a possível homossexualidade das mulheres seria um luxo. 
Ainda que a rede pública pudesse assegurar a contento as vagas para atendimento ginecológico, persistiriam questões relativas à natureza dos programas desenvolvidos. Com relação aos programas de DST /Aids, as lésbicas seriam menos contempladas, porque desenvolveriam mais comumente as D ST em geral e não a Aids, sobre a qual recaem os programas.

O utro aspecto da vulnerabilidade programática das lésbicas é que, por mais que os programas de D ST / Aids estivessem se esforçando e trabal hando de forma crescente a partir da lógica das "práticas de risco" e não dos "grupos de risco", al gumas rotinas desenvolvidas pel os programas traduzi riam al guma sobrevivência daquela primeira lógica, como na distribuição dos preservativos femininos, que permanecia circunscrita a profissionais do sexo ea "mulheres em situações especiais".

Q uando o que se tinha em perspectiva era o Programa de Atenção Integral à Saúde da M ulher (PAISM ), as dificuldades não cessaram. As entrevistas foram consensuais na afirmação da inadequação da atenção dispensada às lésbicas, porque a preocupação do Programa continuaria sen do a saúde reprodutiva em detrimento da saúde sexual, as mulheres sendo absorvidas apenas enquanto mães. M esmo quando o foco era evitar a gravidez, as mulheres permaneciam compreendidas apenas em sua dimensão reprodutiva, não sendo aproveitados os espaços de planejamento familiar para a discussão de questões mais amplas relativas à sexualidade eaos direitos sexuais. 0 pressuposto era o de que mulheres que fazem sexo com homens são absolutamente heterossexuais e sempre o serão.

O s programas de atenção à mulher também falhariam por al egarem que não existe demanda das lésbicas mas, ao mesmo tempo, não desenvolverem estudos e pesquisas capazes de promover a visibilidade lésbica no sistema. 0 fato de não haver pesquisas seria determinante da permanência de mitos difundidos por al guns profissionais, como o de que como o esperma foi "feito para lavar o útero", por isso o útero das lésbicas nunca élavado, e assim elas pegariam mais doenças (relatado por um médico).

O problema da acessibilidade das lésbicas aos serviços de saúdefoi um problema apontado como de maior complexidade do que aparenta. Ele envolveria e mobilizaria tensões em torno da revelação ou não da identidade, pois mesmo quando al guns gruposorganizados (que trabal ham de forma rotineira a necessidade de revelação da identidade) ofereciam serviços particulares com gratuidade às lésbicas desejosas e/ ou necessitadas de consultas ginecológicas, o problema nem 
sempre era resolvido. Esbarrava-se no receio e na vergonha de enfrentar um profissional que, a priori, conheceria a identidade sexual.

Também no SUS como um todo, foi apontada uma grande resistência em abordar a inclusão das lésbicas para além dos programas de D ST /Aids, ainda que al guns outros programas pudessem guardar relação direta com suas necessidades. D e forma bastante contraditória, as lésbicas ainda encontram resistência à sua inclusão nos programas de DST / Aids por não constituírem um "grupo de risco" mas também encontrariam em outros programas, por serem vistas como um "grupo de risco" apenas para D ST /Aids, numa visível tautologia.

0 mau relacionamento com os profissionais de saúde foi um dos pontos mais destacados tanto nos atendimentos públicos quanto privados. Embora o silêncio, a assepsia, a beleza do ambientee o tempo dispensado às consultas dos consultórios privados pudessem funcionar quase sempre como um atenuante para atendimentos incapazes de contemplar plenamente as necessidades de saúde das lésbicas. A relação médico-paciente foi representada como um espaço de infrações éticas silenciadas pelo medo e pela vergonha. A maioria dos ginecologistas seria negligente no tocante à atenção à saúde das lésbicas, particularmenteno que se refere ao monitoramento dos possíveis riscos de infecção. o corre o reconhecimento, inclusive pelos profissionais de saúde, da necessidade de treinamento especializado, a fim de que fossem capazes de abordar as lésbicas de uma forma mais qualificada e respeitosa. 0 problema do desrespeito seria no entanto algo que transcenderia as lésbicas e diria respeito às limitações da formação médica.

O s/as entrevistados/as deram destaque ao despreparo dos médicos para o trato de questões relativas à sexualidade em geral, além da homossexualidade especificamente. Tal despreparo seapresentaria tanto na recusa em discutir questões "subjetivas" e no menosprezo de informações desta ordem, quanto na ignorância de recomendações técnicas e estratégias preventivas relacionadas às práticas sexuais. A negligênciatambém estaria associada à ausência, neles, de "tecnologias emocionais" capazes de criar uma ambientação para a discussão do tema da homossexualidade nas consultas e a uma certa estreiteza do universo médico que lhes impediria de, a partir da revelação do comportamento homossexual, fornecer informações úteis à saúde dos indivíduos consi derando os elementos fornecidos pela cliente.

Alguns médicos realizariam um verdadeiro esforço para manter fidelidade ao protocolo genérico a partir do qual estruturam suas consultas para mulheres: 
mulheres que não Ihes falam desua orientação sexual, a despeito da sua insatisfação. A negligência foi assim também apontada como a omissão dos profissionais, potencialmente capaz de transformar o "corpo lésbico" num corpo doente ou de levá-lo à morte, um argumento queultrapassa a prevenção de D ST eAids dizendo respeito à qualidade da atenção em saúde.

O s profissionais seriam omissos ao não perguntarem se uma paciente H IV positivo, por exemplo, é homossexual, e no caso de contágio, não avisando da necessidade de medicamentos para a parceira. 0 despreparo técnico, embora afete diretamente as lésbicas quando se põem diantede um médico incapaz de prescrever, por exemplo, a assepsia relativa ao uso de acessórios sexuais, poderia afetar muitas pessoas que partilham de práticas semel hantes e não são lésbicas.

0 fato de os médicos desconhecerem as práticas lésbicas e as formas de tratálas, colaboraria para a criação de argumentos falaciosos de que al gumas D ST têm incidência maior entre elas. A maior falácia apontada residiria no fato de que, na verdade, o tratamento é feito com uma única mulher de um casal (o médico não pergunta e/ou deduz que não é necessário medicar a parceira sexual), permitindo a ocorrência da reinfecção. 0 despreparo técnico se manifestaria contudo, para além da escolha dos procedimentos terapêuticos, mas no próprio olhar do profissional de saúde, que seria ordinariamente um olhar generalizante sobre as pessoas, incapaz de perceber as "especificidades" tanto sexuais, como raciaise outras. Além de generalizante e etnocêntrico, este olhar treinado por séculos de tradição cartesiana, seria também um olhar que, por perseguir obstinadamente a objetividade dos conceitos, se fez míopena percepção das formas como indivíduos e grupos recriam, por exemplo, suas identidades sexuais.

A maioria dos ginecologistas teria dificuldade de proporcionar um ambiente adequado à revelação dos comportamentos sexuais, bem como uma escuta capaz de proporcionar o resgate da história pessoal de suas pacientes, sobretudo sem a manifestação de julgamentos morais. 0 questionamento, portanto, é da atitude médica, notadamente da anamnese. Por isso haveria que ser criada uma outra forma deanamnese que excluísse "perguntas fechadas" quenão dão a possibilidade de a paciente "se abrir". 0 reconhecimento de com quem está lidando, através do uso de perguntas abertas, permitiria ao médico perceber as diferenças e adaptar tratamentos e discurso às especificidades do sujeito. 
Para os entrevistados, emborajáfosse possível identificar uma crescente maioria de profissionais se esforçando para não demonstrar espanto nem aversão face à revelação da homossexualidade de suas pacientes, tal reação também não seria necessariamente sinônimo de boa qualidade do atendimento. U ma reação dos profissionais de saúde muito destacada pelos entrevistados, foi a de desconsiderar a informação acerca da orientação sexual como relevanteà consulta ginecológica. A consequência seria a desatenção aos riscos e queixas da paciente, por total desinformação sobre o que dizer nestes momentos. $\mathrm{N}$ esses casos, o profissional manifestaria - ainda que não desejasse - negligência.

Alguns entrevistados sugeriram entretanto, que também seria responsabilidade da paciente a melhoria da relação com o médico, utilizando-se para isso da própria recusa a permanecerem atendidas no caso de preconceito e/ ou negligência. Tal postura estaria em franca oposição a formas degerenciar a vida sexual diferentes da "militante", que apela para a necessidade de "saída do armário" em todos os espaços da vida.

A recusa do atendimento por um médico desrespeitoso, negligente ou incapacitado seria uma atitude que também esbarraria na objetividade do SU S, onde escolher o profissional éfrequentemente uma impossibilidade. Vai de encontro também à dificuldade das próprias lésbicas de assumirem uma postura reativa frente ao histórico poder dosmédicos, mesmo quando a personagem em questão é uma "fancha" que afirma sua identidade em vários outros espaços.

\section{Considerações finais}

A realização desta pesquisa em 2004, apontou para o significativo papel desempenhado até aí pelo Estado no fortalecimento do movimento de lésbicas e na configuração da demanda por saúde sexual deste segmento identitário. Foi flagrante que a participação do Estado ficou circunscrita aos programas de D ST e Aids, especialmenteno nível federal. I mpõem-se, portanto, abordagens diversificadas das demandas trazidas por este segmento, dentro e fora do setor saúde.

É necessário buscar articulações mais fortes e cooperativas entre o movimento de lésbicas e a academia, a fim de que a visibilidadelésbica seja extensiva à produção teórica da nossa sociedade e para que esta produção tenha maior relevância política para este segmento. Além disso, o movimento social sai em vantagem quando passa a dispor de argumentos técnicos e científicos que sirvam de base para suas demandas, especialmente no campo da saúde pública. Por isso, é fundamental a 
participação estatal no estímulo a estudos acadêmicos, especialmente os epidemiológicos, capazes de permitir a comparação das realidades brasileiras com estudos internacionais semelhantes, o que no campo da literatura médica é indispensável. Estes estudos podem contribuir tanto para o desenvolvimento e avaliação das ações de enfrentamento às D ST e Aids capazes de contemplar as necessidades das mulheres que se autodefinem como lésbicas, quanto para a identificação deoutros agravos à saúde que possam ser condicionados pela orientação sexual dos indivíduos. Para a busca destes "outros agravos", impõem-se, por exemplo, investigações que questionem o impacto da estigmatização vivida por al gumas lésbicas na saúde mental, o que tem sido apontado com bastante ênfase nOSSEN ALEs (Seminário N acional deLésbicas) eoutros encontros do movimento como um campo fértil para pesquisas.

A contribuição da antropologia da saúde é inestimável na produção desses estudos, sobretudo por proporcionar um olhar crítico, uma vez que o discurso médico e sua pretensão de universalidade cartesiana têm, em geral, grandes dificuldades para fazêlo.

No que tange às contribuições das Ciências Sociais, é importante 0 desdobramento em estudos de pelo menos duas grandes discussões emergentes neste trabalho. A primeira delas - que implica diretamente a maneira com que muitas lésbicas se vêem e são vistas, como portadoras de um corpo infenso a D ST eAids - vem do fato dequea afirmação identitária nem sempre equivale às práticas sexuai s pressupostas. O u seja, autodeclarar-se lésbica não significa necessariamente abster-se de relações afetivo-sexuais com homens, heterossexuais ou gays.

O utra discussão a ser exploradaéa do paradigma educativo quevem modelando as ações preventivas das DST e Aids entre lésbicas. A ausência de informações sobre sexualidade, e sobretudo, sobre saúde, foi um dos principais argumentos acerca da vulnerabilidade das lésbicas, tanto individual quanto social. Esta é quase uma unanimidadeentreasativistas, principalmenteentreasquefazem partedeorganizações cujo público vem da periferia da cidade e/ ou de camadas populares. N estes casos, a desinformação é claramente associada à origem de classe e al gumas vezes à identidade racial das lésbicas: lésbicas negras e pardas moradoras das regiões periféricas da cidade deteriam menosinformaçõessobreseus corpos, em especial sobre oscuidadosnecessários à preservação da saúde sexual. Tais mulheres estariam sendo vitimadas de múltiplas formas, por serem mulheres quetiveram pouca possibilidadede escolher ter ou não ter 
filhos, por viverem em regiões segregadas das cidades, por não terem autonomia financeira e também por não deterem informações às vezes essenciais sobre higiene e auto-cuidado. Por conta da existência destas múltiplas formas de opressão, as ativistas são afirmativas danecessidade da educação como véculo para a conquista da autonomia necessária à ruptura com essas condições de vida.

O eixo fundamental do paradigma educativo proposto tem repousado no princípio de que a obtenção de informações racionais sobre riscos e sobre formas de evitá-los é, por si só, produtora de novos e desejáveis comportamentos (sexo seguro ou mais seguro). Trata-se de uma relação equivocada entre "fornecer informações eobter mudanças comportamentais", na contramão da literatura recente sobreAids, que demonstra quea mudança de comportamento nem sempre éuma variável do acesso à informação. Vem dos próprios entrevistados a afirmação de que, também entre as lésbicas, o acesso a dispositivos educacionais nem sempre corresponde à efetiva adoção de táticas preventivas.

$\mathrm{N}$ ão obstante, é preciso aumentar o acesso a informações sobre D ST / Aids às lésbicas se o que se deseja éa redução da vulnerabilidade, mas permanece estratégico na disseminação de informações o papel ocupado pelo sociedade civil organizada na produção de ações mais eficazes pelo Estado. São os grupos que funcionam como polo de atratividade das mulheres afiliadas a uma identidade lésbica ou bissexual e constituem, ao lado das empresas do mercado rosa, as únicas agências capazes de executar o trabalho de agregação identitária. Por mais que o discurso médico "alternativo" forneça argumentos técnicos sobre a vulnerabilidade, ele é impotente sozinho, face ao desafio de mudar comportamentos, o que, em última instância, é muito mais: é o desafio de influir na cultura sexual das lésbicas.

Por outro lado, os próprios grupos precisam refletir sobre suas estratégias interventivas. É flagrantea indisposição/insatisfação de muitasfrequentadoras dos grupos de convivência em serem alvo de uma pedagogia sexual claramente domesticadora. Para muitas, os grupos deixam de trabal har com outras questões de vital importância produzidas pela estigmatização e partem de uma perspectiva individualista e adventícia que deposita na mudança de comportamento as expectativas de resposta às demandas de saúde das lésbicas. D este modo, quando o movimento de lésbicas prioriza a crítica da rede de atenção à saúde (serviços de saúde) e os posicionamentos éticos dos profissionais de saúde na relação com as lésbicas, está mais próximo do que deseja sua base. 
N os grupos predomina ainda uma perspectiva que guarda estreita relação com as bases de recrutamento de suas lideranças, de que estes grupos são células de uma militância política nacional e quiçá internacional pelos direitos das lésbicas e bissexuais. Entretanto, para as frequentadoras ativas destes espaços, 0 grupo quase sempre se reveste de outros si gnificados, como o de espaço para que se agreguem novas bagagens culturais, como espaço de troca de vivências e busca de soluções para dramas pessoais, como espaço alternativo de busca de colisões amorosas. Tais significados muitas das vezes entram em choque, produzindo rupturas, dissidências e extinção dos grupos. M uitos deles se encontram hoje confrontados com a necessidade de transformar suas reuniões em espaços de exercício da política, mas de maneiras menos ortodoxas e capazes de conciliar diferentes necessidades das participantes.

O s grupos exclusi vamente lésbicos, no entanto, permanecem muito solitários na busca de alternativas de sobrevivência e atendimento de suas necessidades, num cenário de crescente profissionalização das O N G sque atuam no campo dos direitos humanos. Suas alternativas de financiamento são escassas efalta assessoria especializada na construção eencaminhamento dos projetos desenvolvidos. Também neste caso, o papel do Estado é fundamental no fomento e no apoio técnico às iniciativas de intervenção com este segmento. Trata-se de ações que fatalmente conferirão maior equidade à forma como historicamente o Estado brasileiro se relacionou com as mulheres lésbicas e bissexuais.

0 fomento às ações talvez possa não mais circunscrever o campo da atenção à saúde das lésbicas à saúde sexual e às DST/Aids, ou mesmo possa permitir a consideração do que este artigo demonstra quea vulnerabilidadenão se resumeao plano das práticas sexuais, masé determinada pelo conjunto das condições de vida a que muitas lésbicas são submetidas, especialmente as de camadas populares e/ ou racialmente discriminadas. Enfrentar este plano da vulnerabilidade implica desenvolver ações na área de educação que inibam a prática do bulling no sistema educacional, que estimulem as práticas de educação sexual nas escolas, em cumprimento aos PCN s. Também énecessária a intervenção consistente do Poder Público junto às famílias na contenção das violências e maus tratos a que muitas lésbicas são submetidas, seja através da ação das próprias escolas, dos Conselhos Tutelares, das equipes dos Programas de Saúde da Família (PSFs) ou das equipes profissionais de monitoramento familiar ligadas ao Sistema Ú nico de Assistência 
Social (SU AS). N o plano das relações detrabal ho, épreciso considerar a orientação sexual como um elemento que pode incidir negativamente na busca ou na manutenção de um emprego e oferecer aos indivíduos e grupos opções de enfrentamento dessa questão, inclusive com a produção dealternativas de geração de emprego e renda que contemplem as necessidades específicas deste segmento em cada contexto sociocultural. D e forma complementar, é preciso criar maiores espaços de acesso à justiça e mecanismos de proteção em casos de violação de direitos (como casas abrigo), rediscutir o atendimento das lésbicas em órgãos públicos ligados à Segurança Pública, como as delegacias de polícia, os abrigos para adolescentes, as penitenciárias.

É importante ressaltar que, na maioria das vezes, o que se sugere não é a construção de alternativas de atendimento especificamente dirigidas às lésbicas, mas a visibilidade e discussão do tema no espaço das políticas existentes. Para isso, é imprescindível a constituição de sérias e duradouras parcerias entre o sistema público e o não-governamental ( 0 N G s e grupos). Como não existem políticas e canais públicos de inclusão das lésbicas claramente definidos ${ }^{18}$ e a interlocução do movimento com o Estado se efetiva deforma pessoal eesporádica, um dos grandes obstáculos à incorporação das demandas de saúde das lésbicas, mesmo junto aos programas deDST /Aids, éo fato de estarem sempre ao sabor das gestões. M udanças eleitorais, conjunturas governamentais e restrições orçamentárias são permanentes variáveis a que o movimento tem de se submeter.

Por outro lado, parece se consolidar nos modelos de prevenção governamentais a visão da existência de um espaço pré-definido para as O N G s: o de agentes que realizam trabalhos mediante projetos (focados em um público que elas mesmas recrutam) que ocorrem apenas no espaço das próprias 0 N G s enão articulados em outros espaços de execução das políticas de prevenção, como as instituições de saúde e/ou as associações comunitárias. A ampliação do espaço de atuação das O N G straria, por exemplo, a grande vantagem deformar uma mal ha de prevenção em saúde com maior capilaridade e especificidade. 


\section{Referências}

AL M EID A, G. S. de. D a invisi bilidadeà vulnerabilidade: percursos do "corpo lésbico" na cena brasileira face à possibilidade de infecção por DST e Aids. 2005, 344 p. Tese (D outorado em SaúdeC oletiva) - Instituto de M edicinaSocial, U niversidade do Estado do Rio de Janeiro, Rio de Janeiro, 2005.

CAST ELLS, M anuel. 0 poder da identidade A Eradal nformação: economia, sociedadeecultura, v. 2. São Paulo: Paz eTerra, 1999.

CO LETIVO DE FEM IN ISTAS LESBICAS. Folder: U m pouco do quevocêgostaria desaber sobre.. lésbicas, 1994.

COSTA, Jurandir F. A inocência eo víci o: estudos sobreo homoerotismo. Rio de Janeiro: Relume D umará, 1992.

FRY, Peter; M acRAE, Edward. 0 queéhomossexualidade. São Paulo: Brasiliense, 1987 (C oleção PrimeirosPassos).

GIO RD AN I, Annecy T.; BU EN O , Sônia M . V. A prática do homossexualismo entremulheres detentasea vulnerabilidadeàsD ST /AID S. Jornal Brasileiro deD oençasSexualmenteTransmissíveis, São Paulo, v. 5, n. 13, p. 23-35, 2001.

GOH N , M ariada G lória. Teorias dos M ovimentosSociais paradigmas clássicosecontemporâneos. São Paulo: Loyola, 2000.

M AN N , J. C omo avaliar avulnerabilidadeàinfecção pelo H IV eAIDS. In: PARKER, R., GALVÃO, J.; PEDRO SA, J. S. (orgs.). A AID S noM undo. Rio de Janeiro, Relume-D umará, 1993.

M OTT, Luiz. 0 Lesbianismo no Brasil. Porto Alegre: M ercado Aberto, 1987.

PARKER, Richard G .; AG GLETO N , Peter. Estigma, discriminação eAids Rio de aneiro: ABIA, 2001 (C oleção ABIA - Cidadania eD ireitos, n. 1).

RO H DEN , Fabíola. A artedeenganar a natureza: contracepção, aborto einfanticídio no início do século XX. Rio deJaneiro: Fiocruz, 2003.

VAN CE, CaroleS. A antropologia redescobrea sexualidade: um comentário teórico. Phyśs Revista deSaúdeC oletiva, Rio deJaneiro: I M S/U ERJ, v. 5, n. 1, 1995.

WEEK S, J effrey. $O$ corpo ea sexualidade. In: LO U RO, G uacira Lopes(org.). 0 corpo educado: pedagogias da sexualidade. Belo H orizonte: Autêntica, 1999.

ZAQ UIEU , Anna PaulaV. Na encruzilhada dasdiferenças: política, dasseserelações degênero na construção do ativi smo contra a Aids- 1989-1997. 2002. D issertação (M estrado em H istória) Programa dePós G raduação em H istória, U niversidadeF ederal Fluminense, N iterói, 2002.

W IKIPED IA EN CICLO PED IA VIRT U AL. D isponível em: <http://pt.wikipedia.org/wiki/ P\%C 3\%Algina_principal> Acesso em: jun.2007. 


\section{$\mathrm{N}$ otas}

${ }^{1}$ Parker e Aggleton buscam em Foucault e Pierre Bourdieu os elementos para pensarem as relações entre cultura e poder. Seu objetivo era examinar como sistemas sociais estratificados de hierarquia e dominação persistiam e se reproduziam pelas gerações. $\mathrm{N}$ o interior desses sistemas, todos os significados e práticas culturais englobam interesses e funcionam de forma a aumentar as distinções sociais entre indivíduos, grupos e instituições" (PARKER; AG GLET O N , 2001, p. 15).

2 Tomo de empréstimo a concepção de Costa, para quem homoerotismo, é a "possibilidade que têm certos sujeitos de sentir diversos tipos de atração erótica ou de se relacionar fisicamente de diversas maneiras com outros do mesmo sexo biológico. Em outras palavras, o homem homoeroticamente orientado não é, como facilmente acreditamos, alguém que possui um traço ou conjunto de traços psíquicos que determinariam a inevitável e necessária expressão da sexualidade homoerótica em quem quer que os possuísse. A particularidade do homoerotismo em nossa cultura não se deve à pretensa uniformidade psíquica da estrutura do desejo comum a todos os homossexuais; deve-se, sugiro, ao fato de ser uma experiência subjetiva moralmente desaprovada pelo ideal sexual da maioria [...]. Tenho a intenção de mostrar que o 'homem homossexual' nada maisé que uma realidade linguística, enão uma realidade natural" (COSTA, 1992, p. 22-23).

${ }^{3} \mathrm{~A}$ respeito das experiências históricas de interven ção higienista sobre o "corpo lésbico" no Brasil, vale conferir o trabalho de M ott (1987), infelizmente não reeditado.

${ }^{4}$ Prefiro aqui enfatizar o plural, pois são vários os argumentos e gradações em que se pode pensar esta vulnerabilidade.

${ }^{5}$ Tais critérios se incluem entre os sugeridos por M ann (1993, p. 275-300) para a avaliação do grau de vulnerabilidade.

${ }^{6}$ Ver por exemplo Giordani e Bueno (2001) ,que fazem um estudo sobre lésbicas em presídios e a cartilha da O N G Centro de D ocumentação e Informação Coisa de M ulher (CED O ICO M ), "Solto a Voz da Prisão", queé um material produzido nos anos 90 durante realização de projeto de intervenção no interior de unidades penais femininas do Rio de Janeiro.

7 Zaquieu (2000, p. 39), ainda que ressalte que as áreas de atuação das O N G s-Aids são bastante variadas, aponta a solidariedade como um ponto comum a todas e agrupa os campos de ação das mesmas em cinco: "monitoramento das políticas públicas de controle, prevenção e assistência à doença; divulgação de informações cientificamente embasadas sobre a epidemia; luta contra o preconceito e a discriminação dos portadores do vírus; apoio e solidariedade para os soropositivos e doentes de Aids".

${ }^{8}$ Vale a afirmação de C astells (1999, p. 95) de que "os movimentos sociais podem ser conservadores, revolucionários, ambas as coisas, ou nenhuma delas", pois "não existe uma direção predeterminada no fenômeno da evolução social" e "o único sentido da história é a história que nos faz sentido". Portanto, do ponto de vista analítico, não há movimentos sociais bons ou maus. Todos eles são sintomas denossas sociedades, e todos causam impacto nas estruturas sociais, em diferentes graus de intensidade e resultados distintos que devem ser determinados por meio de pesquisas". 
${ }_{9}^{9}$ Algumas oriundas do feminismo negro e de outros movimentos sociais.

${ }^{10} \mathrm{~N}$ a Plataforma de Ação definida ao final da Conferência, o feminismo mundial conseguiu manter 0 conceito de "direitos sexuais", ainda que não se utilize o termo, bem como a afirmação do direito das mulheres de controlarem e decidirem livre e responsavelmente sobre sua sexualidade e capacidade reprodutiva, frentea oposições conservadoras, mas houve um resultado negativo, em relação à aprovação do reconhecimento da existência de mulheres com orientação homossexual e o direito delas de expressarem sua sexualidade sem sofrer discriminação.

${ }^{11} \mathrm{~N}$ o sentido de permitir a emergência de uma discussão sobre suas características e sobre o que estas características podem apontar para uma vulnerabilidade.

12 Responsável, entre outras iniciativas, pela continuidade do Grupo M atricial, espaço exclusivo de interlocução das lésbicas com a CN -DST / Aids durante a década de 1990 (e até recentemente) e pela organização e publicação do Guia de Prevenção das D ST /Aids e Cidadania para H omossexuais (2002).

13 Tropismo é o movimento de curvatura orientado em relação a um agente externo. Podem ser positivos - em direção ao agente externo excitante; e negativos - em direção oposta ao agente externo excitante (WIKIPED IA, 2007).

${ }^{14} \mathrm{Em}$ quase todos os materiais destinados a lésbicas analisados, havia uma referência ao uso de drogas.

${ }^{15}$ O N G lésbica paulistana.

${ }^{16}$ Incentivo à adaptação de materiais variados na busca de práticas sexuais seguras (ou mais seguras) e defácil execução: preservativos masculinos, femininos e "cling film" (plástico utilizado com frequência na cozinha para embalagem de frutas e legumes) recortados com tesoura, luvas cirúrgicas e películas de látex para uso odontológico. Estes materiais são indicados para utilização no sexo oral ena penetração anal e vaginal por mulheres.

${ }^{17}$ Analisando as origens da nossa atual compreensão do "homossexual", Costa (2002, p. 42) volta-se ao século XIX e à obra de Balzac e 0 scar W ilde, elementos da construção de uma "faceta positiva", a fantasia do homossexual revolucionário e anticonformista. Esta fantasia teria contaminado inúmeros artistas e pensadores, consolidando a partir daí uma identidade gay que é, sob muitos aspectos, herdeira da idealização romântica do "homossexual outsider".

${ }^{18}$ No dia 31 deagosto de2006, a LBL, ABG LT (Associação Brasileira de Gays, Lésbicas eTransgêneros), a AN TRA e várias entidades de usuários do SU S reuniram-se em Brasília para eleição das entidades que tomaram assento no Conselho N acional de Saúde (CN S) no triênio 2006-2009. Pela primeira vez, 0 movimento LGBT teve assento naquele Conselho. $\mathrm{N}$ a ocasião foram definidas propostas para a atuação do movimento no Conselho, entre eles: a construção de um seminário "Saúde GLBT ", a criação de uma comissão de saúde GLBT dentro do CNS, a capacitação de pessoas GLBT para o controle social dos municípios e estados, a proposição e o incentivo à realização de pesquisas para a saúde GLBT, 0 acolhimento de denúncias dos segmentos pelos representantes e a participação em outros grupos de trabalho do M inistério da Saúde. Certamente tal conquista demarca um novo campo de influência do movimento de lésbicas no âmbito federal de definição da política de saúde e precisa ser monitorado. 


\section{Abstract}

Arguments on the possibility of ST D infection and Aidsamong women that define themselvesaslesbians

The academic production motivated by H IV and Aids epidemic has impelled research works related to the sexuality, configurating new investigation fields, mainly about gays. H owever, in Brazil, the academic production which addresses to the ST D vulnerability, taking the lesbian identity into account, is not significant. The sexual health of women, expected to be heterosexual, was connected to the unique preoccupation about reproduction along the course of policies in terms of the attention to women's health, even facing Aids. Increasingly, considering the heterosexual female sexuality, female homosexuality has tended, in the Brazilian society, to become invisible in the medical / gynecologic speech. The epidemic contributed to this continuing invisibility, due to strong beliefs in which the "lesbian body" would be the only one immune to the infection through the sexual via. The hypothesis guiding this paper is based on the idea that lesbians vulnerability is the "passport" for affirmation/inclusion of a certain identity mark in public policies agenda.

> Key words: Female homosexuality; sexually communicable diseases; Aids; Brazil. 